\title{
Productivity Growth in the Medium Size Malaysian-industry Level: Primal and Dual Approaches
}

\author{
Abdol Samad Nawi ${ }^{1}$, Irwan Bin Ismail ${ }^{1}$, Zainuddin Zakaria ${ }^{1}$, Jannah Munirah Md Noor ${ }^{1}$, Bashir Ahmad Bin \\ Shabir Ahmad ${ }^{1}$, Nik Fakrul Hazri ${ }^{1}$, Wan Anisabanum Salleh ${ }^{1}$, Mohd Tajul Hasnan Mohd Tajuddin ${ }^{2} \&$ Nur \\ Raihana Mohd Sallem² \\ ${ }^{1}$ Business \& Management Faculty, Universiti Teknologi MARA (UiTM), Dungun, Malaysia \\ ${ }^{2}$ Faculty of Accountancy, Universiti Teknologi MARA (UiTM), Dungun, Malaysia \\ Correspondence: Abdol Samad Nawi, Business \& Management Faculty, Universiti Teknologi MARA (UiTM), \\ Dungun Campus, 23000 Dungun, Malaysia. Tel: 60-9-8400-101/60-17-386-3537. E-mail: \\ samad252@tganu.uitm.edu.my
}

Received: May 31, 2012 Accepted: July 3, 2012 Online Published: September 27, 2012

doi:10.5539/ass.v8n12p249 URL: http://dx.doi.org/10.5539/ass.v8n12p249

\begin{abstract}
This paper investigates the theoretical relationship between the primal and dual Total Factor Productivity (TFP) from the accounting measurement perspective and also assesses their accuracy in measuring unobserved TFP growth in the presence of market power (MP) and non constant returns to scale (NCRTS) in the case of the medium sized Malaysian industries. In support of this, this paper uses an empirical method to estimate TFP growth by using medium sized Malaysian manufacturing data at 5-digit SIC (Standard Industrial Classification) level. In order to achieve this objective, this paper first tests whether the sample of medium sized Malaysian industries have constant factor shares in total revenue. T-tests have been used to examine the hypothesis stating that factor shares in total revenue are constant over time. Finally, this paper compares the estimates of TFP growth to those of primal and dual TFP accounting measures.
\end{abstract}

Keywords: productivity, market power, non constant returns to scale

\section{Introduction}

Accounting for differences in growth rates between countries has been the focus of substantial literature in recent years. One branch of this literature has sought to distinguish between growth that can be attributed to increased usage of factor inputs and growth that can be attributed to an increase in total factor productivity (TFP). This literature has been plagued by measurement problems, as it is not possible to observe TFP. One approach has been to use an aggregate production function, from which a measurement of TFP can be generated as a residual (often known as the "Solow Residual"). Alternatively, TFP may be measured by examining the dual nature of the production function - i.e., the production-cost relationship. The equivalence of these two measures depends critically on some crucial assumptions embedded in neoclassical production theory.

The assumptions of perfect competition (PC) and constant returns to scale (CRTS), as well as the theoretical results derived in a framework that incorporates them, are often applied in empirical studies, including microeconomic studies based on firm-level data. However, recent theoretical advances as well as the related empirical research have shown that the departure from these standard assumptions may have important implications with respect to the derived theoretical behavioural characteristics and the validity of the conclusions based on the related empirical analysis. Relaxing some of the assumptions of PC and CRTS has led to various extensions of the standard neoclassical results.

Traditionally, the measurement of the Solow residual has been based on standard neoclassical assumptions. This dates back to Solow $(1956,1957,1960)$, in which an aggregate production function was identified with a Hicks-neutral shift parameter and CRTS $\left(Q_{t}=\Theta_{t} F\left(K_{t}, N_{t}\right)\right)_{t}$ where $\mathrm{t}$ denotes time, aggregate gross output (Q) is produced from aggregate inputs consisting of capital $(\mathrm{K})$ and Labour $(\mathrm{N})$. The level of the Solow residual is represented in the Hicks-neutral $(\Theta)$ parameter and is almost always characterised as "output augmenting" and "technical change".

Among the first papers that challenged some of the standard neoclassical assumptions was the seminal work by 
Hall (1988). He questioned the assumption of PC in product markets, and tested the equality of prices and marginal costs (under the assumption of CRTS) using longitudinal industry-level data for this purpose. His empirical results provided strong evidence against the joint hypothesis of PC and CRTS. He also showed that the primal Solow residual based on quantities of factor inputs can be decomposed into two parts: price mark-up and technological change components. In another seminal paper, Roeger (1995) further elaborated Hall's approach, preserving the assumption of CRTS. He established that, similar to the primal, the dual Solow residual which is based on prices and quantities of factor inputs can also be decomposed into two components. Moreover, he argued that the presence of market power (MP) - a violation of the conditions of PC - induces a wedge between the primal and the dual residuals.

The works of Hall and Roeger inspired a series of empirical studies such as Carlaw and Lipsey (2003), Lipsey and Carlaw (2002), Hulten (2000), Basu and Fernald (1997), and Jorgenson, Gollop and Fraumeni (1987). All of them have argued that unobserved TFP growth is not an appropriate measure of technological change as Hall had claimed in his paper. Under the assumptions of CRTS and PC, unobserved TFP growth has been measured in the literature using traditional primal TFP measurement (Solow, 1957) and traditional dual TFP measurement (Christensen, Jorgenson and Lau, 1973). The TFP measurements based on primal and dual approaches should be equivalent because of the duality of production functions and cost functions

Young $(1992,1995,1998)$ and Hsieh $(1999,2002)$ have undertaken research into the aggregate productivity growth of Singapore, attempting to understand the relationship between the primal and dual TFP growth measurements and also their accuracy in measuring unobserved TFP growth. Young $(1992,1995)$, by using primal TFP growth accounting, shows that there was in fact no aggregate TFP growth in Singapore. Hsieh (1999, 2002), shows only a 2 percent TFP growth in Singapore by utilising dual TFP growth accounting measurement. The research carried out by Hsieh also shows that primal and dual TFP growth should be equal, when based on national income data. Hsieh and Young's findings however, are different due to the inaccuracy of the data and to differences in the way investment is treated, i.e. whether it is treated as exogenous or endogenous in the production function. Unfortunately, the findings of Hsieh are still not sufficiently convincing to assume that both TFP accounting measures should be equal to unobserved TFP growth.

As a result of this, the objectives of this paper are to study the theoretical relationship between the primal and dual TFP from the accounting measurement perspective and assess their accuracy in measuring unobserved TFP growth in the presence of MP and NCRTS in the context of the medium size Malaysian-industry level. In order to achieve this objective, this paper relaxes both the assumption of CRTS and PC and shows that the wedge between the two TFP accounting measures depends on the growth rates of factor shares in total revenue. Thus, if factor shares in total revenue remain constant, then one will expect that the difference between the growth rates of primal and dual TFP will vanish, even in the presence of MP and/or NCRTS.

In support of this, this paper will use an empirical method to estimate TFP growth by using Malaysian manufacturing data at 5-digit SIC (Standard Industrial Classification) level, when both primal and dual TFP accounting measurements fail due to MP and NCRTS. In order to reach this objective, these papers will first tests whether the industries have constant factor shares in total revenue in the sample. The $t$-tests will be used to examine the hypothesis that factor shares in total revenue are constant over time. If the $t$-tests fail to reject the null hypothesis of constant factor shares in total revenue, then this will indicate that the growth rate of primal TFP will be equal to the growth rate of dual TFP, even in the presence of MP and/or NCRTS. Secondly, the paper will estimate average TFP growth, and scale coefficients according to the structural model of production and cost functions. Finally, this paper will compare the estimates of TFP growth to those of primal and dual TFP accounting measures.

The paper is organised as follows. Section 2 discusses review of literature, measurement of productivity and the theoretical background. Section 3 discusses the estimation framework. Section 4 discusses data description and analysis. While Section 5 provides the conclusion.

\section{Review of Literature, Measurement of Productivity and Theoretical Background}

\subsection{Growth Model and TFP}

The first explanation of technological progress is commonly attributed to Solow (1956). In his growth model, technology is something accessible to everybody free of charge. A different view of technological progress considered in Solow (1957) and by many others thereafter, suggests that the previous model overlooks the interaction between capital accumulation and technological progress. Other scholars (Beckers, 1964; Lucas, 1988) have highlighted the importance of human capital in explaining technological progress. More recently, various authors (Romer, 1986, 1990; Grossman and Helpman, 1991) have claimed that technological progress 
can be better modelled by a combination of external effects and increasing returns. There is a vast empirical literature dealing with TFP. Based on growth accounting measures Abramovitz (1956) carried out one of the first attempts in determining the sources of TFP. His results indicated that the main sources of the productivity growth in the U.S.A. were still unidentified

\subsection{Technological Change Measurement}

In Solow's model of economic growth, Solow assumed an aggregate Cobb-Douglas production function that converts capital $(\mathrm{Kt})$ and labour $(\mathrm{Nt})$ inputs into output $(\mathrm{Qt})$. Technological change is assumed to be Hicks-neutral so that shifts in the level of output do not change the marginal rate of substitution of the inputs. With the additional assumption of CRTS, the Cobb-Douglas production function takes the form $Q_{t}=\Theta_{t} K_{t}^{\alpha} N_{t}^{1-\alpha}$ where $\Theta_{t}$ is a measure of the cumulative effect of technological change over time, and $\alpha \in(0,1)$ is the share of capital in production. The production function $Q_{t}$ may be written in per capita terms in the following way:

$$
\frac{Q_{t}}{N_{t}}=\Theta_{t}\left(\frac{K_{t}}{N_{t}}\right)^{\alpha}
$$

Letting $q_{t}=\frac{Q_{t}}{N_{t}}$ and $k_{t}=\frac{K_{t}}{N_{t}}$, Solow showed that $\Delta \Theta_{t}=\Delta q_{t}-\alpha \Delta k_{t}$, where the operator $\Delta$ indicates a percentage change and lower case denotes the natural logarithms transform.

\subsection{Measurement of TFP Growth from the Traditional Neo-classical Production Function (Primal Approaches)}

The traditional framework for the measurement of TFP growth was developed by Solow $(1956,1957,1960)$ and furthered by Denison (1967, 1979), Grilliches and Jorgenson (1966) and Jorgenson et al. (1987).

Assume that each sector, indexed by $i$, has at time $t$ the following production function,

where;

$$
Q_{i t}=\Theta_{i t} F_{i}\left(K_{i t} N_{i t}\right)
$$

$Q_{i t}=$ Output at time $\mathrm{t}$ in sector i

$K_{i t}=$ Capital input at time $\mathrm{t}$ in sector $\mathrm{i}$

$N_{i t}=$ Labour input at time $\mathrm{t}$ in sector $\mathrm{i}$

$\Theta_{i t}=$ Solow residual TFP at time $t$ in sector $i$ or an index of Hicks-neutral technical change.

The logarithmic differential with respect to $t$ can be written as,

$$
\frac{\partial \ln Q_{i t}\left(K_{i t}, N_{i t}, t\right)}{\partial t}=\left(\frac{\partial(\ln Q)}{\partial(\ln K)} \bullet \frac{\ln K}{\ln Q}\right) \cdot \frac{\partial(\ln K)}{\partial t}+\left(\frac{\partial(\ln Q)}{\partial(\ln N)} \bullet \frac{\ln N}{\ln Q}\right) \bullet \frac{\partial(\ln N)}{\partial t}+\frac{\partial(\ln Q)}{\partial(\ln \Theta)} \bullet \frac{\partial(\ln \Theta)}{\partial t}
$$

where;

$$
\begin{aligned}
& \Phi_{K}=\left(\frac{\partial(\ln Q)}{\partial(\ln K)} \bullet \frac{\ln K}{\ln Q}\right) \text { is the relative share of capital input } \\
& \Phi_{N}=\left(\frac{\partial(\ln Q)}{\partial(\ln N)} \bullet \frac{\ln N}{\ln Q}\right) \text { is the relative share of labour input } \\
& \hat{\Theta}=\frac{\partial(\ln Q)}{\partial(\ln \Theta)} \text { is unity since it is a Hicks-neutral shift parameter } \\
& \hat{Q}=\frac{\partial(\ln Q)}{\partial t} \text { is the growth rate of output } \\
& \hat{K}=\frac{\partial(\ln K)}{\partial t} \text { is the growth rate of capital input } \\
& \hat{N}=\frac{\partial(\ln N)}{\partial t} \text { is the growth rate of labour input }
\end{aligned}
$$

Thus when time derivatives are indicated; the rate of growth of output can be shown as 


$$
\hat{Q}=\Phi_{K} K+\Phi_{N} N+\Theta
$$

Therefore, TFP growth is measured as the residual of output growth after accounting for the growth of the inputs.

$$
\Theta=\hat{Q}-\Phi_{K} K-\Phi_{N} N
$$

Or, Solow Residual (SR) primal $=\hat{Q}-\Phi_{K} K-\Phi_{N} N$

This Equation above is the measurement of TFP growth based on the quantities information approach, otherwise known as the primal approach.

2.4 Measurement of TFP Growth from the Traditional Neoclassical Cost Function (Primal and Dual Approaches)

The primal and dual approaches of TFP growth can be derived either from the production function or from cost function. Initially, we can look at the cost function approach in which output is equal to the payments to the factors of production.

$$
\mathrm{PQ}=\mathrm{rK}+\mathrm{wN}
$$

where

$$
\begin{aligned}
& \mathrm{r}=\text { price of capital } \\
& \mathrm{W}=\text { price of labour } \\
& \mathrm{PQ}=\text { Total Revenue } \\
& \mathrm{K}=\text { Capital inputs } \\
& \mathrm{N}=\text { Labour inputs }
\end{aligned}
$$

If differentiating both side of equation above with respect to time, the equation will be:

$$
\frac{\partial P Q}{\partial t}=\left(r \bullet \frac{\partial K}{\partial t}+K \bullet \frac{\partial r}{\partial t}\right)+\left(N \bullet \frac{\partial w}{\partial t}+w \bullet \frac{\partial N}{\partial t}\right)
$$

Now dividing equation above by $\mathrm{PQ}$, the result is;

$$
\frac{\frac{\partial P Q}{\partial t}}{P Q}=\left(\frac{r}{P Q} \bullet \frac{\partial K}{\partial t}+\frac{K}{P Q} \bullet \frac{\partial r}{\partial t}\right)+\left(\frac{N}{P Q} \bullet \frac{\partial w}{\partial t}+\frac{w}{P Q} \bullet \frac{\partial N}{\partial t}\right)
$$

Rearrange equation above as;

$$
=\frac{r K}{P Q}\left(\frac{\frac{\partial K}{\partial t}}{K}+\frac{\frac{\partial r}{\partial t}}{r}\right)+\frac{w N}{P Q}\left(\frac{\frac{\partial w}{\partial t}}{w}+\frac{\frac{\partial N}{\partial t}}{N}\right)
$$

where;

$$
\begin{aligned}
& \frac{r K}{P Q}=\text { shares of capital in total revenue. } \\
& \frac{w N}{P Q}=\text { shares of labour in total revenue. }
\end{aligned}
$$

Now, replacing the terms involving the growth rates of factor quantities on the left-hand side of the equation, obtaining;

$$
\frac{\frac{\partial P Q}{\partial t}}{P Q}-\frac{r K}{P Q}\left(\frac{\frac{\partial K}{\partial t}}{K}\right)-\frac{w N}{P Q}\left(\frac{\frac{\partial N}{\partial t}}{N}\right)=\frac{r K}{P Q}\left(\frac{\frac{\partial r}{\partial t}}{r}\right)+\frac{w N}{P Q}\left(\frac{\frac{\partial w}{\partial t}}{w}\right)
$$

Then, the primal estimate of the Solow (1957) residual is the growth rate of output minus the share-weighted growth in capital and labour inputs. 


$$
\frac{\frac{\partial P Q}{\partial t}}{P Q}-\frac{r K}{P Q}\left(\frac{\frac{\partial K}{\partial t}}{K}\right)-\frac{w N}{P Q}\left(\frac{\frac{\partial N}{\partial t}}{N}\right)
$$

The dual estimate of Solow (1957) residual is the share-weighted growth in capital and labour prices.

$$
\frac{r K}{P Q}\left(\frac{\frac{\partial r}{\partial t}}{r}\right)+\frac{w N}{P Q}\left(\frac{\frac{\partial w}{\partial t}}{w}\right)
$$

Both Equations above are based on prices and quantities of factor inputs information, and therefore this is known as the dual approach.

\subsection{The Relationship between Primal and Dual TFP from the Traditional Neoclassical Model}

The traditional assumptions of a neoclassical model of production are:

1) Producers are in long-run equilibrium

2) Technology exhibits CRTS

3) Output and input markets are perfectly competitive

4) Factors are utilised at a constant rate

According to the assumptions, let $\mathrm{i}$ be the industry index and $\mathrm{t}$ be the time index; therefore, the relationship between growth rate of output, $\hat{Q}_{i t}$, the growth rate of labour input, $\hat{N}_{i t}$, and the growth rate capital input, $\hat{K}_{i t}$, can be represented by Equation below

$$
\hat{Q}_{i t}=\Phi_{i K} K_{i t}+\Phi_{i N} N_{i t}+\Theta_{i t}
$$

where $\hat{\Theta}_{i t}$ is the growth rate of Hicks neutral productivity, $\Phi_{i K}$ and $\Phi_{i N}$ are the elasticity of output with respect to capital and labour input.

Hence according to Hall (1988), the equation above can be rewritten as below

$$
\hat{\Theta}_{i t}=\left(\frac{Q_{i t}}{K_{i t}}\right)-\left(1-\Omega_{i K}\right)\left(\frac{N_{i t}}{K_{i t}}\right)
$$

Where the left hand side of equation is the rate of Hicks-neutral technical progress $(\Delta \log (\Theta))$. Solow recommended evaluating the left hand side in order to measure the rate of growth of TFP. This measure has come to be known as TFP growth because, unlike measures that consider only output and labour input, it accounts for capital input and, in a more general form, for all other types of inputs.

The first term on the right hand side of equation $\left(\frac{Q}{K}\right)$ is the growth rate of output per capital $\left(\Delta \log \left(\frac{Q}{K}\right)\right)$ and in the second term, $\Omega_{i K}$ is the share of capital in total revenue (ratio of compensation rK to total revenue PQ), and $\left(\frac{N}{K}\right)$ is the rate of growth of the labour per capital $\left(\Delta \log \left(\frac{N}{K}\right)\right)$. Whilst $\Omega_{N}=\frac{w N}{P Q}$ is the share of labour in total revenue.

Therefore, the right hand side of equation has become known as the "Solow Residual" (SR).

According to the dual approach of production theory, a similar relationship also exists between the growth rate of the output price, $\hat{P}_{i t}$, the growth rate of wages, $\hat{w}_{i t}$, and the rental price, $\hat{r}_{i t}$ :

$$
P_{i t}=\Omega_{i K} r_{i t}+\Omega_{i N} w_{i t}-\Theta_{i t}
$$

Thus,

$$
\hat{\Theta}_{i t}=\left(1-\Omega_{i K}\right)\left(\frac{r_{i t}}{w_{i t}}\right)-\left(\frac{P_{i t}}{r_{i t}}\right)
$$


Where the first right hand side (RHS) of equation $\left(\frac{r_{i t}}{w_{i t}}\right)$ is the growth rate of rental price per wage $\left(\Delta \log \left(\frac{r}{w}\right)\right)$ multiplied by $\left(1-\Omega_{i K}\right)$ is the share of labour in total revenue (or 1 minus the ratio of compensation rK to total revenue PQ) and the second RHS, $\left(\frac{P_{i t}}{r_{i t}}\right)$ is the growth rate of output price per rental price $\left(\Delta \log \left(\frac{P}{r}\right)\right)$.

Therefore, defining the growth rate of primal TFP and the growth rate of dual TFP according to the following equation as defined by Hall (1988):

$$
T F P_{i t} \text { primal } \Rightarrow \hat{\Theta}=\left(\frac{Q_{i t}}{K_{i t}}\right)-\left(1-\Omega_{i K}\right)\left(\frac{N_{i t}}{K_{i t}}\right)
$$

Re-expressing equation above with the convention that

$$
x=\frac{X}{K}
$$

Where

$$
q=\frac{Q}{K}
$$

And

$$
\pi=\frac{N}{K}
$$

Obtain

$$
T F P_{\text {it }} \text { primal } \Rightarrow \hat{\Theta}_{i t}=q_{i t}-\left(1-\Omega_{i K}\right) \pi_{i t}
$$

Primal TFP growth is measured by the difference between the growth rate of output and the revenue share-weighted average of inputs.

$$
T F P_{i t} d u a l \Rightarrow \hat{\Theta}_{i t}=\left(1-\Omega_{i K}\right)\left(\frac{r_{i t}}{w_{i t}}\right)-\left(\frac{P_{i t}}{r_{i t}}\right)
$$

Dual TFP growth is measured by the difference between the growth rate of wage rental ratio and rental price ratio.

Under the assumptions of CRTS and PC, the growth rate of the two TFP (primal and dual) measures are theoretically identical, and they measure the unobserved TFP growth, $\hat{\Theta}_{i t}$, precisely.

\section{The Estimation Framework Moving from the Traditional to Generalised Neoclassical Approach}

\subsection{Primal Analysis}

Returning to the previous equation in which it was assumed that each sector, indexed by $i$, at time $t$, the following production function applies,

$$
Q_{i t}=\Theta_{i t} F_{i}\left(K_{i t}, N_{i t}\right)
$$

By substitution and manipulation, the equation above can be further reformulated to achieve the following

$$
T F P_{\ddot{u}} \text { primal }=\Theta_{\dot{u}}+\left(\omega_{i}-1\right)\left(1-\Omega_{i \bar{K}}\right) \hat{\pi}_{\dot{u} t}+\left(Z_{i}-1\right) K_{\dot{u} t}
$$

Equation above leads to the following proposition:

\section{Proposition 1}

Let $\hat{N}_{i t}>0$ and $\hat{K}_{i t}>\hat{N}_{i t}$. The growth rate of traditional primal TFP will be less than the growth rate of generalised primal TFP if the mark up is greater than 1 and the organisation faces decreasing returns to scale. If the organisation faces increasing returns to scale and mark up $>1$, the growth rate of traditional primal TFP will be less than or more than the growth rate of generalised primal TFP. 


\section{Proof}

Given $\hat{N}_{i t}>0$ and $\hat{K}_{i t}>\hat{N}_{i t}$, then $\hat{\pi}_{i t}<0$, followed by $\omega_{i}>1(\mathrm{MP})$ and $Z_{i}<1$. So TFP ${ }_{i t}$ primal $<\hat{\Theta}_{i t}$

Intuitively, if the firm is capital intensive relative to labour, the existence of MP and decreasing returns to scale implies that the growth rate of traditional primal TFP growth will be lower than the generalised primal TFP growth. The above proposition restates the results of Hall $(1988,1990)$, where he shows that MP may cause the Solow residual to be procyclical and correlated with some aggregate demand variables.

\subsection{Dual Analysis}

Initially starts with the Homogeneity of the Cost Function.

$C(w, r, F(N, K))=w N+r K$ is a general cost function, and $Q=\Theta F(N, K)$,

If $\mathrm{F}$ is homogeneous of degree $\mathrm{Z}$ in $(\mathrm{N}, \mathrm{K})$,

as a result

$\mathrm{C}$ is homogeneous of degree $\frac{1}{Z}$ in $\mathrm{F}$

$\mathrm{C}$ is homogeneous of degree $\frac{1}{Z}$ in $\mathrm{Q}$

Let $m=\frac{\partial C}{\partial Q}$, then $m=\frac{1}{Z} \frac{C}{Q}$

Based on the above properties, Homogeneity of the Cost Function can be rewritten as general cost function,

$$
C\left(w_{i t}, r_{i t}, F_{i}\left(N_{i t}, K_{i t}\right)\right)=w_{i t} N_{i t}+r_{i t} K_{i t}
$$

By substitution and manipulation, Equation above can be further modified to achieve the following

$$
\operatorname{TFP}_{\overline{i t}} d u a l=\hat{\Theta}_{\overline{i t}}+\left(\omega_{\bar{i}}-1\right)\left(1-\Omega_{\overline{Z K}}\right)\left(\frac{r_{i t}}{w_{i t}}\right)+\left(Z_{\bar{i}}-1\right)\left(\frac{P_{i t} Q_{i t}}{r_{i t}}\right)
$$

The equation leads to the following proposition:

\section{Proposition 2}

Let $w_{i t}>r_{i t}>0$ and $P_{i t} Q_{i t}>\hat{r}_{i t}$. The growth rate of traditional dual TFP will be less than the growth rate of generalised TFP, if the mark-up is greater than 1 and returns to scale less than 1 . However, if the organisation faces increasing returns to scale and mark up $>1$, the growth rate of traditional dual TFP will be less than or more than the growth rate of generalised dual TFP.

\section{Proof}

Given $w_{i t}>r_{i t}>0$, and $P_{i t} Q_{i t}>\hat{r}_{i t}$

Thus $\left(\frac{r_{i t}}{w_{i t}}\right)<0$ and $\left(\frac{P_{i t} Q_{i t}}{r_{i t}}\right)>0$, therefore $\omega_{i}>1(\mathrm{MP})$ and $Z_{i}<1$ or $>1$.

Therefore

$$
T F P_{i t} d u a l<\hat{\Theta}_{i t}
$$

Intuitively, the above proposition shows that, with the right conditions, both MP and decreasing returns to scale may result in traditional dual TFP growth underestimating the generalised TFP growth. Notice that by maintaining the assumption of CRTS, that is setting $\mathrm{Zi}=1$, Roeger (1995), it shows that MP causes the traditional dual TFP growth to underestimate generalised dual TFP growth. In other words, Roeger considers only one of the scenarios of proposition 2 that of MP. However, by considering both conditions, MP and NCRTS, it can also cause the traditional dual TFP to underestimate the generalised TFP growth.

\section{The Difference}

The difference between the two measured growth rates of TFP can be derived by subtracting 


$$
T F P_{i t} \text { primal }-T F P_{i t} d u a l=\left(\omega_{i}-1\right)\left(1-\Omega_{i K}\right)\left(\frac{w_{i t} N_{i t}}{r_{i t} K_{i t}}\right)+\left(\left(Z_{i}-1\right)\left(\frac{r_{i t} K_{i t}}{P_{i t} Q_{i t}}\right)\right)
$$

Intuitively, in theory, the presence of MP and NCRTS creates a possible wedge (Roeger, 1995) between the two measures. However, given that the factor shares in total revenue are mostly constant in the real world, the right-hand side of the above equation is practically nil even in the presence of MP and NCRTS.

\section{Proposition 3}

If the shares of labour and capital in total revenue are constant, then the growth rate of traditional or generalised primal TFP will be equal to the growth rate of traditional or generalised dual TFP, even in the presence of MP and/or NCRTS.

\section{Proof}

Input share of labour in total revenue $=\left(\frac{w_{i t} N_{i t}}{P_{i t} Q_{i t}}\right)$

Input share of capital in total revenue $=\left(\frac{r_{i t} K_{i t}}{P_{i t} Q_{i t}}\right)$

If the input shares of labour and capital in total revenue are constant, so

$$
\left(\frac{w_{i t} N_{i t}}{P_{i t} Q_{i t}}\right)=\left(\frac{r_{i t} K_{i t}}{P_{i t} Q_{i t}}\right)
$$

Thus $\left(\frac{w_{i t} N_{i t}}{r_{i t} K_{i t}}\right)=0$ or the ratio of shares of labour and capital will be practically nil.

Then $T F P_{i t}$ primal $-T F P_{i t} d u a l=0$.

\section{Estimation Strategy}

Endogeneity will arise, if the $\alpha_{i N}$ and $\beta_{i K}$ parameters are estimated using the Ordinary Least Squares (OLS) regression method. TFP growth initially will be estimated in the presence of MP and NCRTS by using OLS regression methods. This can be done by applying equations below, which are extensions of the primal and dual Hall regressions, in order to estimate mark-up and returns to scale coefficients with regard to the model specified,

$$
\begin{gathered}
q_{i t}=\Theta_{i 1}+\alpha_{i 2}\left(1-\Omega_{i K}\right) \pi_{i t}+\alpha_{i 3} K_{i t} \\
\left(\frac{r_{i t}}{P_{i t}}\right)=\hat{\Theta}_{i 1}+\beta_{i 2}\left(1-\Omega_{i K}\right)\left(\frac{r_{i t}}{w_{i t}}\right)+\beta_{i 3}\left(\frac{P_{i t} Q_{i t}}{r_{i t}}\right)
\end{gathered}
$$

Where

$\hat{q}_{i t}$ is the growth rate of output, $\hat{\pi}_{i t}$ is growth rate of the labour per capital ratio, $\left(\frac{r_{i t}}{P_{i t}}\right)$ is the growth rate output price per rental price ratio, $\left(\frac{r_{i t}}{w_{i t}}\right)$ is the growth rate of rental price per wage ratio, $\left(\frac{P_{i t} Q_{i t}}{r_{i t}}\right)$ is the growth rate total revenue per rental price ratio, $\hat{\Theta}_{i t}$ is the growth rate of Hicks neutral productivity and $\Omega_{i K}$ is the share of capital in total revenue.

Meanwhile $\alpha_{i 2}$ and $\beta_{i 2}$ will be the estimated values of the industry-specific mark-ups, and $\alpha_{i 3}$ and $\beta_{i 3}$ will be the estimated values of the industry-specific returns to scale coefficients. In order for the primal and dual regressions to be equivalent, the following constraints must hold: 


$$
\begin{aligned}
& \alpha_{2}=\beta_{2} \\
& \alpha_{3}=\beta_{3}
\end{aligned}
$$

Subsequently, the previous equations will display endogeneity. The growth rate of technological progress, $\hat{\Theta}_{i t}$, enters a firm's first-order condition for profit maximisation (as well as that of cost minimisation), which determines the input demand and also output of the firm. So, without overcoming this problem, $\hat{\Theta}_{i t}$, the least squares estimates for the coefficients of the growth rate of labour per unit of capital and the growth rate of capital will be biased upward. This problem was first initially discussed by Marschak and Andrew (1944). Firms choose inputs knowing their own level of productivity, which is unobservable to the econometrician. A least squares regression of output on inputs will give inconsistent estimates of the production function coefficients.

Furthermore, as shown in Olley and Pakes (1996), there will be a selection bias in the model because of the pattern of firms' entry and exit. Productive firms will stay in the business, while unproductive firms choose to exit. However, larger firms may be better able to survive short periods of low productivity, so without overcoming the problem of surviving probability of firms in the industry, least squares estimates for capital growth will be biased downwards. According to Olley and Pakes (1996) for estimating productivity effects of restructuring in the U.S. telecommunications equipment industry, they not only addressed the simultaneity of inputs and unobserved productivity, but also argued that correlation of exit from the sample with inputs would lead to an additional sample selection bias. In other words, if low productivity firms tend to exit and the exit-thresholds show a decrease in capital, selection will bias the least squares estimate of the capital coefficient downward.

\section{Fixed Effect Correction}

Assuming that the Hicks neutral technological progress parameter is a random variable of the following form:

$$
\begin{gathered}
\Theta_{i t}=\Theta_{i 0^{\theta_{i t} t}} \\
\hat{\Theta}_{i t}=\varphi_{i t}=\sigma_{i}+\lambda_{t}+u_{i t}
\end{gathered}
$$

in which $\Theta_{i 0}$ is the technological level of industry $\mathrm{i}$ at the beginning, period 0 , and $\varphi_{i t}$ is the growth rate of technological progress. So, the growth rate of the technological progress of industry in period ' $t$ ' consists of an industry-specific growth rate, $\sigma_{i}$, and a period-specific growth rate, $\lambda_{t}$, which captures the macroeconomic shock that is common across industries in the same period, plus a white noise, $u_{i t}$, that is a classical random error with zero mean and $\sigma^{2}$ variance.

By applying substitution method, to obtain

$$
\begin{gathered}
q_{t}=\sigma_{i}+\lambda_{t}+\left(\omega_{i}-1\right)\left(1-\Omega_{i K}\right) \pi_{i t}+\left(Z_{i}-1\right) \hat{K}_{i t}+u_{i t}^{P} \\
\left(\frac{r_{i t}}{P_{i t}}\right)=\sigma_{i}+\lambda_{i}+\left(\omega_{i}-1\right)\left(1-\Omega_{i K}\right)\left(\frac{r_{i t}}{w_{i t}}\right)+\left(Z_{i}-1\right)\left(\frac{P_{i t} Q_{i t}}{r_{i t}}\right)+u_{i t}^{D}
\end{gathered}
$$

Where $u_{i t}^{P}$ and $u_{i t}^{D}$ will capture both additive measurement errors specific to $\hat{q}_{i t}$ and $\left(\frac{r_{i t}}{P_{i t}}\right)$ and the white noise productivity shock, $u_{i t}$.

Applying the cross equation restriction, the equation may be stacked to give the formulation as below:

$$
\left[\begin{array}{c}
\hat{q}_{i 1} \\
\vdots \\
\hat{q}_{i T} \\
\left(\frac{r_{i 1}}{P_{i 1}}\right. \\
\vdots \\
\left(\frac{r_{i T}}{P_{i T}}\right)
\end{array}\right]=\sigma_{i 1}+\sum_{t=2}^{T} \lambda_{t} D_{t}+\left(\omega_{i}-1\right)\left[\begin{array}{c}
\left(1-\Omega_{i}\right) \hat{\pi}_{i 1} \\
\vdots \\
\left(1-\Omega_{i}\right) \hat{\pi}_{i T} \\
\left(1-\Omega_{i}\right)\left(\frac{r_{i 1}}{w_{i 1}}\right) \\
\vdots \\
\left(1-\Omega_{i}\right)\left(\frac{r_{i T}}{w_{i T}}\right)
\end{array}\right]+\left(Z_{i}-1\right)\left[\begin{array}{c}
\hat{K}_{i 1} \\
\vdots \\
\hat{K}_{i T} \\
\left(\frac{P_{i 1} Q_{i 1}}{r_{i 1}}\right) \\
\vdots \\
\left(\frac{P_{i T} Q_{i T}}{r_{i T}}\right)
\end{array}\right]+\mathrm{u}_{i}
$$

or, $\hat{Q}_{i}=\sigma_{i 1}+\sum_{T=2}^{T} \lambda_{t} D_{t}+\left(\omega_{i}-1\right) N K_{i}+\left(Z_{i}-1\right) K P Q r_{i}+u_{i}$ 
In the equation above, bold characters denote vectors. $D_{t}$ is a $2 \mathrm{~T} \times 1$ indicator vector that has an entry equal to one for period $t$, and zero otherwise.

\section{Data Description and Analysis}

This paper utilised the data that has been collected and reported to the Department of Statistics, Malaysia from a census of Manufacturing Industries, for the period 1975-1999. The reporting unit for the census is the establishment. An Establishment is defined as "An economic unit that engages, under a single ownership or control, that is, under single legal entity, in one, or predominantly one kind of economic activity at a single physical location". The number of establishments in the sample ranges from some 3819 establishments in 1975 to 17,570 establishments in 1999 . The total number of establishments during the period of study from 1975 to 1999 is 187,193 establishments.

The sample that was studied was a medium sized industry (industries on average with more than 50 but less than 150 employees per establishment) which falls into the category of an average establishment. Average establishments refer to industries with certain employment size which is deemed as average the by Department of Statistics, Malaysia.

Table 1 presents the summary of mean values of the main variables that have been used in the computation of traditional primal and dual TFP growth. Table 1 was used to estimate generalised primal and dual TFP growth of the industry in Malaysian manufacturing at 5-digit SIC level from 1975-1999. The values represent the average annual growth rates from 1975 to 1999 in percentage terms.

Table 1. Data at a glance in Malaysian manufacturing at 5-digit industry with medium size industry

\begin{tabular}{|c|c|c|c|c|c|c|c|}
\hline \multicolumn{8}{|c|}{ Average Annual Growth Rate (\%) of } \\
\hline Industry (1) & $\begin{array}{l}\text { Ln Output } \\
\text { Capital Ratio } \\
\text { (2) }\end{array}$ & $\begin{array}{l}\text { Ln Real } \\
\text { Rental Price } \\
\text { Ratio (3) }\end{array}$ & $\begin{array}{l}\text { Ln Labour } \\
\text { Capital Ratio } \\
\text { (4) }\end{array}$ & $\begin{array}{l}\text { Ln Wage } \\
\text { Rental } \\
\text { Ratio (5) }\end{array}$ & $\begin{array}{l}\text { Ln } \\
\text { Capital } \\
\text { (6) }\end{array}$ & $\begin{array}{l}\text { Ln Revenue } \\
\text { Rental Ratio } \\
\text { (7) }\end{array}$ & $\begin{array}{l}\text { Ln } \\
\text { Output } \\
(8)\end{array}$ \\
\hline $\begin{array}{c}\text { Food, Beverages and } \\
\text { Tobacco }\end{array}$ & -0.02 & -0.03 & 0.00 & 0.00 & 0.16 & 0.08 & 0.14 \\
\hline $\begin{array}{l}\text { Textiles, Apparel \& } \\
\text { Leather }\end{array}$ & -0.04 & -0.15 & -0.01 & -0.01 & 0.18 & -0.03 & 0.16 \\
\hline Wood Products & -0.02 & -0.03 & -0.01 & 0.00 & 0.12 & 0.04 & 0.10 \\
\hline $\begin{array}{l}\text { Paper Product, Printing } \\
\text { and Publishing }\end{array}$ & -0.04 & -0.06 & -0.01 & 0.00 & 0.19 & 0.06 & 0.15 \\
\hline $\begin{array}{c}\text { Chemical, Petroleum, } \\
\text { Coal, Rubber and } \\
\text { Plastics }\end{array}$ & -0.11 & -0.08 & -0.01 & 0.00 & 0.23 & 0.03 & 0.13 \\
\hline $\begin{array}{l}\text { Non-Metallic Mineral } \\
\text { Products }\end{array}$ & 0.01 & -0.04 & -0.01 & 0.00 & 0.16 & 0.10 & 0.17 \\
\hline $\begin{array}{l}\text { Metallic Mineral } \\
\text { Products }\end{array}$ & -0.05 & -0.09 & -0.01 & 0.00 & 0.18 & 0.02 & 0.14 \\
\hline $\begin{array}{l}\text { Machinery \& } \\
\text { Equipment }\end{array}$ & -0.05 & -0.31 & -0.03 & -0.02 & 0.34 & -0.05 & 0.30 \\
\hline Other Manufacturing & 0.32 & -0.13 & -0.01 & -0.07 & 0.33 & -0.01 & 0.15 \\
\hline
\end{tabular}

Notes: Unless otherwise stated, all values represents the average annual growth rates from 1975 to 1999 in percentage terms

Output of an industry is defined as the gross value of output at 5-digit SIC code for each industry, obtained from the Annual Industrial Survey Department of Statistics (Malaysia) and is deflated with the 1989 sectoral Producer Price Index (PPI) in order to get the real value.

Labour is measured by the number of full-time and part-time employees. Salaries and wages paid refer to cash payments, including bonuses, commissions, overtime payments, cost of living allowances and other allowances made to all paid employees during the year in question. In this paper, the assumption of homogeneous labour input is imposed.

In this paper, capital stock data is not available for Malaysia. Thus, capital input is measured as the value of fixed 
assets as at the end of a calendar year. Assets cover all goods, new or used, tangible or intangible, that have a normal economic life span of more than one year (e.g. land, building, machinery and equipment, including transport equipment). The values of these fixed assets are deflated with the 1989 sectoral PPI in order to get the real value.

Rental prices are incorporated according to the user costs method. An estimate of the user cost of physical capital, $\mathrm{r}$ is thus required. Following Hall and Jorgensen (1967), the following formula is applied:

$$
r_{t}=P_{t-1}+P_{t} d_{t}-\left(P_{t}-P_{t-1}\right)
$$

Where $r$ is the rental price, $\mathrm{P}$ is the price index for new capital goods, $\mathrm{q}$ is the net rate of return and $\mathrm{d}$ is the rate of depreciation.

The rate of depreciation used is 0.03 for non-residential structures (Hulten and Wyckoff, 1996), 0.0152 for other structures (Fraumeni, 1997), 0.3 for transportation equipment (Hulten and Wyckoff 1996) and 0.12 for other machinery and equipment (Hulten and Wyckoff, 1966). Defining capital income to equal nominal value added less labour compensation, and given information about depreciation, holding gains and capital stock, the net rate of return is estimated residually as:

$$
q_{t}=\frac{\text { capitalincome }-\left(P_{t} d_{t}-\left(P_{t}-P_{t-1}\right)\right) K_{t-1}}{P_{t-1} K_{t-1}}
$$

Where $\mathrm{K}$ is the real capital stock and PK the nominal capital stock.

Unless otherwise stated, most of the data needed for the regression has been obtained from various years of the Report of the Department of Statistics, Malaysia.

\subsection{Average Growth of Factor Shares in Value Added for Medium Size Industry}

Table 2 presents the time series data and statistics of the average growth of the labour share in value added for medium size Malaysian manufacturing industries from 1975 to 1999. According to proposition 3, if the factor shares in total revenue are constant, then the growth rate of primal TFP will be equal to the growth rate of dual TFP, even in the presence of MP and/or NCRTS. The t-tests have been used to formally examine the proposition that the factor shares in value added are constant over time. If the factor shares in total revenue do not display a trend or have not been changing over time, then the ratio growth rate of factor shares in value added will be nil. Subsequently, if t-tests fail to reject a null hypothesis of constant, the factor shares in value added, then this will indicate that the growth rate primal TFP will be equal to the growth rate of dual TFP, even in the presence of MP and/or NCRTS.

The last two columns of Table 2 presents the value of t-tests and average growth factor shares in value added for medium size industry. In detail, the last columns of Table 2 demonstrates a constant average growth of the factor shares in value added. The second last column of Table 2 presents the value of t-tests and it shows that the constant average growth of the factor shares in value added cannot be rejected for any of the industries in the sample. This indicate that all industries in the sample accept a nil growth in labour and capital shares in total revenue, therefore, the null hypotheses of constant average growth of labour and capital in value added are not being rejected. The last column of Table 4.2 shows that the average growth of the labour share in value added ranges from nil to 0.03 percent, showing similar patterns to those that Roeger (1995) has found using U.S.A. manufacturing data. 
Table 2. Average growth labour share in value added with medium size industry, 1975-1999

\begin{tabular}{|c|c|c|c|c|c|c|c|c|c|c|}
\hline & $1975-197$ & 981-1985 & 986-1990 & 991-1995 & 996-1999 & Min Max & Mean & S.D. $\mathrm{t}$ & -statistics & $\begin{array}{l}\text { Average } \\
\text { Growth }\end{array}$ \\
\hline $\begin{array}{c}\text { Food, } \\
\text { Beverages and } \\
\text { Tobacco }\end{array}$ & -0.01 & 0.02 & 0.01 & 0.01 & 0.06 & -0.370 .44 & 0.02 & 0.20 & -0.33 & 0.02 \\
\hline $\begin{array}{l}\text { Textiles, } \\
\text { Apparel \& } \\
\text { Leather }\end{array}$ & -0.07 & 0.03 & 0.01 & 0.09 & 0.03 & -0.330 .46 & 0.02 & 0.19 & -0.76 & 0.02 \\
\hline $\begin{array}{l}\text { Wood } \\
\text { Products }\end{array}$ & 0.05 & -0.01 & 0.06 & 0.04 & -0.01 & -0.270 .30 & 0.03 & 0.14 & -0.05 & 0.03 \\
\hline $\begin{array}{l}\text { Paper Product, } \\
\text { Printing and } \\
\text { Publishing }\end{array}$ & 0.01 & 0.03 & 0.03 & 0.05 & 0.02 & -0.300 .30 & 0.03 & 0.13 & 0.09 & 0.03 \\
\hline $\begin{array}{l}\text { Chemical, } \\
\text { Petroleum, } \\
\text { Coal, Rubber } \\
\text { and Plastics }\end{array}$ & 0.04 & 0.00 & 0.01 & 0.05 & 0.00 & -0.360 .44 & 0.02 & 0.19 & -0.01 & 0.03 \\
\hline $\begin{array}{c}\text { Non-Metallic } \\
\text { Mineral } \\
\text { Products }\end{array}$ & 0.06 & -0.06 & 0.03 & 0.06 & 0.05 & -0.530 .43 & 0.03 & 0.19 & -0.71 & 0.03 \\
\hline $\begin{array}{l}\text { Metallic } \\
\text { Mineral } \\
\text { Products }\end{array}$ & -0.03 & -0.13 & 0.04 & 0.08 & 0.10 & -0.540 .29 & 0.00 & 0.18 & 0.30 & 0.00 \\
\hline $\begin{array}{c}\text { Machinery \& } \\
\text { Equipment }\end{array}$ & 0.04 & -0.01 & 0.00 & 0.03 & 0.04 & -0.400 .44 & 0.02 & 0.20 & -0.16 & 0.02 \\
\hline $\begin{array}{c}\text { Other } \\
\text { Manufacturing }\end{array}$ & -0.09 & -0.05 & 0.08 & 0.08 & 0.08 & -0.380 .57 & 0.02 & 0.23 & -1.19 & 0.02 \\
\hline
\end{tabular}

4.2 Decomposition and Estimation of TFP Growth for Medium Size Industry

The primary purpose of this paper is to decompose the sources of traditional primal and dual TFP and generalised primal and dual TFP growth into scale and mark-up effects in the hope of isolating a better measure of technical progress. The results are presented in columns 2 and 3 of Table 3.

In columns 2 and 3 of Table 3, the traditional primal and dual TFP growth measures (Solow framework) are presented where TFP is measured under the assumptions of CRTS and PC. In columns 4 and 5 of Table 3 , the adjusted primal and dual TFP growth is presented where TFP is OLS estimated using under the assumptions of CRTS and MP.

Meanwhile in column 6 and 7 of Table 3, the generalised primal and dual TFP growth is presented where TFP growth is also OLS estimated but under the assumptions of NCRTS and MP.

By stacking both regressions together to estimate primal and dual TFP growth jointly using GMM estimation regression, the result is presented in column 8 and 9 , however in column 8 , TFP is estimated under the assumptions of CRTS and MP but in column 9, TFP is estimated under the assumptions of NCRTS and MP.

A comparison of the different TFP growth measures (columns 2, 3, 6, and 7) in Table 3 reveals that the contributions for the different biases resulting from scale and mark-up are statistically important. By comparing columns 2 and 3 with columns 6 and 7, respectively, the traditional primal and dual TFP growth underestimate the generalised primal and dual TFP growth when the assumptions of NCRTS and MP are relaxed. This finding aimed at providing support to propositions 1 and 2, that the growth rate of traditional primal and dual TFP will be less than the growth rate of generalised primal and dual TFP, respectively. 
Table 3. Decomposition of TFP growth in Malaysia manufacturing industry with medium size industry: 1975-1999

\begin{tabular}{|c|c|c|c|c|c|c|c|c|}
\hline Industry (1) & $\begin{array}{c}\text { Traditional } \\
\text { Primal TFP } \\
\text { (2) }\end{array}$ & $\begin{array}{c}\text { Traditional } \\
\text { Dual TFP } \\
\text { (3) }\end{array}$ & $\begin{array}{c}\text { Adjusted } \\
\text { Primal TFP } \\
(\text { Hall })^{\mathrm{b}}(4)\end{array}$ & $\begin{array}{c}\text { Adjusted Dual } \\
\text { TFP(Roeger) } \\
\text { (5) }\end{array}$ & $\begin{array}{c}\text { Generalis } \\
\text { ed Primal } \\
\operatorname{TFP}^{\mathrm{c}}(6)\end{array}$ & $\begin{array}{l}\text { Generalised } \\
\text { Dual } \operatorname{TFP}^{\mathrm{c}}(7)\end{array}$ & 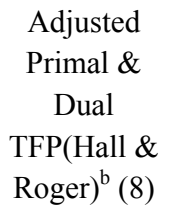 & $\begin{array}{l}\text { Generalised } \\
\text { Primal \& } \\
\text { Dual TFP } \\
\text { (9) }\end{array}$ \\
\hline $\begin{array}{c}\text { Food, Beverages } \\
\text { and Tobacco }\end{array}$ & -0.03 & -0.03 & 0.05 & 0.06 & 0.07 & 0.08 & 0.04 & 0.04 \\
\hline $\begin{array}{l}\text { Textiles, Apparel } \\
\text { \& Leather }\end{array}$ & -0.02 & -0.02 & 0.06 & 0.08 & 0.08 & 0.08 & 0.04 & 0.04 \\
\hline Wood Products & -0.01 & 0.00 & 0.03 & 0.04 & 0.05 & 0.05 & 0.00 & 0.01 \\
\hline $\begin{array}{c}\text { Paper Product, } \\
\text { Printing and } \\
\text { Publishing }\end{array}$ & -0.03 & -0.02 & 0.03 & 0.04 & 0.05 & 0.06 & 0.02 & 0.02 \\
\hline $\begin{array}{c}\text { Chemical, } \\
\text { Petroleum, Coal, } \\
\text { Rubber and } \\
\text { Plastics }\end{array}$ & -0.03 & -0.03 & 0.04 & 0.05 & 0.06 & 0.06 & 0.01 & 0.01 \\
\hline $\begin{array}{c}\text { Non-Metallic } \\
\text { Mineral } \\
\text { Products }\end{array}$ & -0.02 & -0.03 & 0.05 & 0.06 & 0.05 & 0.05 & 0.00 & 0.01 \\
\hline $\begin{array}{l}\text { Metallic Mineral } \\
\text { Products }\end{array}$ & -0.05 & -0.06 & 0.04 & 0.05 & 0.08 & 0.09 & 0.00 & 0.00 \\
\hline $\begin{array}{l}\text { Machinery \& } \\
\text { Equipment }\end{array}$ & -0.01 & -0.01 & 0.07 & 0.08 & 0.09 & 0.09 & 0.02 & 0.02 \\
\hline $\begin{array}{c}\text { Other } \\
\text { Manufacturing }\end{array}$ & -0.05 & -0.05 & 0.05 & 0.06 & 0.19 & 0.20 & 0.02 & 0.02 \\
\hline
\end{tabular}

Note: ${ }^{a}$ Traditional TFP assumes constant returns to scale and perfect competition

${ }^{\mathrm{b}}$ Adjusted TFP assumes constant returns to scale and market power

${ }^{\mathrm{c}}$ Generalised TFP assumes non constant returns to scale and market power

To further illustrate the relationship between the traditional primal and dual TFP, and the generalised primal and dual TFP, this paper has constructed a scatter diagram to present the relationship by plotting these two measurements against each other. The scatter diagrams are as presented in Figure 1 and Figure 2. The scatter diagram in Figure 1 clearly indicates that the relationship between the traditional primal and dual TFP is robustly (positively) related with correlation coefficient of 0.95 for medium industry as shown in Table 4 . Second, a similar pattern can also be observed in the relationship between the generalised primal and dual TFP as shown in Figure 2 for medium size industry with correlation coefficient of 0.99 as indicated in Table 5. Third, Figure 1 and Figure 2 also show the number of industries that are below, above or on the 45 degree line between traditional primal and dual TFP estimation, and generalised primal and dual TFP estimation. Fourth, Figure 1 and Figure 2 also show there is not a consistent tendency for the primal TFP to produce higher or lower estimates than the dual TFP in either traditional or generalised cases. The findings from the scatter diagram and correlation coefficients indicate that scale and mark-up magnitude is important in determining the rate of TFP growth. This finding is in line with the dispositions of Hall (1988), Roeger (1995) and Basu \& Fernald (1997) in their study. 


\section{B. Medium Size Industry}

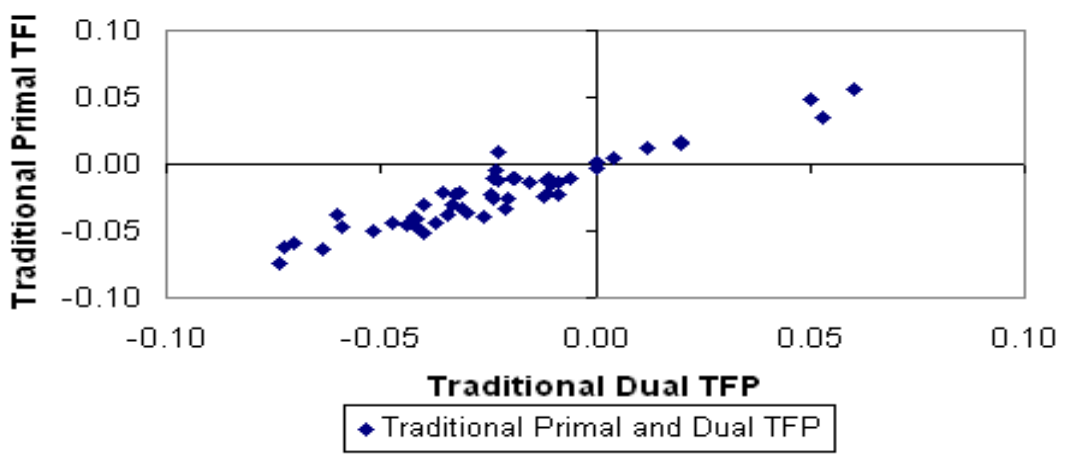

Figure 1. Traditional primal and dual TFP in Malaysian manufacturing at 5-digit industry and size of the industry

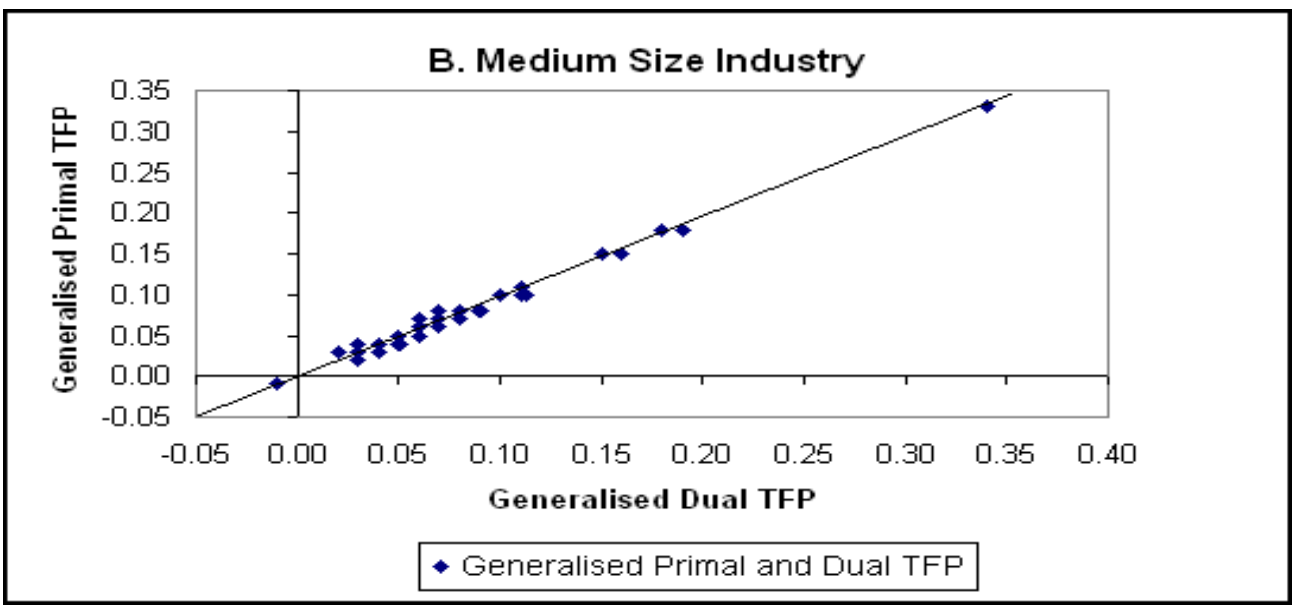

Figure 2. Generalised primal and dual TFP in Malaysian manufacturing at 5-digit Industry and size of the industry

Table 4. Correlation coefficient between traditional primal TFP and traditional dual TFP

\begin{tabular}{|c|c|c|}
\hline & $\begin{array}{c}\text { Traditional Primal TFP (Medium } \\
\text { Size Industry) }\end{array}$ & $\begin{array}{c}\text { Traditional Dual TFP (Medium Size } \\
\text { Industry) }\end{array}$ \\
\hline $\begin{array}{c}\text { Traditional Primal TFP (Medium Size } \\
\text { Industry) }\end{array}$ & 1.00 & $0.947 * * *$ \\
\hline $\begin{array}{c}\text { Traditional Dual TFP (Medium Size } \\
\text { Industry) }\end{array}$ & $0.947 * * *$ & 1.00 \\
\hline Number of Observations & 51 & 51 \\
\hline \multicolumn{3}{|c|}{$* * *$ correlation is significant at the 0.01 level } \\
\hline & $\begin{array}{c}\text { Generalised Primal TFP (Medium } \\
\text { Size Industry) }\end{array}$ & $\begin{array}{c}\text { Generalised Dual TFP (Medium } \\
\text { Size Industry) }\end{array}$ \\
\hline $\begin{array}{c}\text { Generalised Primal TFP (Medium } \\
\text { Size Industry) }\end{array}$ & 1.00 & $0.993 * * *$ \\
\hline $\begin{array}{l}\text { Generalised Dual TFP (Medium Size } \\
\text { Industry) }\end{array}$ & $0.993 * * *$ & 1.00 \\
\hline Number of Observations & 51 & 51 \\
\hline
\end{tabular}

*** correlation is significant at the 0.01 level 


\section{Conclusion}

This paper has made the following contributions to the available literature. Firstly, the paper has proved theoretically and shown empirically, that even in the presence of MP and NCRTS in the medium Malaysian manufacturing industry during the period of study from 1975 to 1999, primal and dual TFP accounting measures are proved to be equal mainly because the factor shares in value added in all industries are relatively constant. Differences between primal and dual TFP, however, can still be observed in a few cases. Similar findings were found in the studies by Young (1995) and Hsieh (2002). This difference was considered as white noise by Young (1995) and could also be due to data inaccuracy as argued by Hsieh (2002). If the factor shares in value added are not constant, then the differences should depend on MP (Roeger, 1995) and/or NCRTS (as suggested by this paper). The inconstancy could also be due to the changes in factor shares and how investment is treated in the production model, as being either endogenous or exogenous (Hall, 1988). The findings from this paper is in contrast with the results obtained by Roeger (1995), which show that MP alone could explain the differences between primal and dual TFP accounting measures in the U.S.A. manufacturing sector.

Secondly, this paper demonstrates that the assumptions of CRTS and PC are essential for both primal and dual TFP in measuring TFP growth for the medium Malaysian manufacturing industry. If these assumptions are violated, both accounting methods could underestimate TFP growth.

Finally, this paper sheds light on the debate between Young $(1992,1995)$ and Hsieh $(1999,2002)$ who argued that the discrepancies at the aggregate level for primal and dual TFP growth are mainly driven by data issues, since factor shares in value added are relatively constant. Thus, Young and Hsieh rejected the possibility that this discrepancy is related to the assumptions used in the estimation. However, from the papers of Hsieh and Young, they found that even at the aggregate level, the two essential assumptions (CRTS and PC) should be supported to show that the primal and dual TFP growth be equal. Nevertheless, the findings of Hsieh and Young are different. For this reason, both Young $(1992,1995)$ and Hsieh $(1999,2002)$ might have underestimated the aggregate TFP growth of Singapore. The findings of this paper show that if we can allow for NCRTS and MP estimating of the TFP growth then the TFP growth would be substantially higher than the accounting measures using either primal or dual methods. Thus, this paper strongly recommends that both assumptions should be taken into consideration in measuring TFP growth.

\section{References}

Abramovitz, M. (1956). Resources and output trends in the U.S. since 1870. American Economic Review, 46, 5-23.

Basu, Susanto, \& John G. Fernald. (1997). Return to scale in U.S. productions: Estimates and implications. Journal of Political Economy, 105(2), 249-283. http://dx.doi.org/10.1086/262073

Beckers, G. S. (1964). Human Capital. Columbia University Press, New York.

Carlaw, Kenneth I., \& Richard G. Lipsey. (2002). Productivity, technology and economic growth: What is the relationship? Unpublished.

Christensen, Laurits R., Jorgenson, Dale W., \& Lau, Lawrence J. (1973). Transcendental Logarithmic Production Frontier. The Review of Economics and Statistic, 55(1), 28-45. http://dx.doi.org/10.2307/1927992

Denison, E. F. (1967). Some Major Issue in Productivity Analysis: An Examination of Estimates by Jorgenson and Griliches. Survey of Current Business, 49, 1-28.

Denison, E. F. (1967). Why Growth Rates Differ: Postwar Experience in Nine Western Countries. Washington, D.C.: Brookings Institute.

Denison, E. F. (1979). Explanation of Declining Productivity Growth. Survey of Current Business, 59(2), 20-35.

Fare Rolf, \& Primont Daniel. (1995). Multi-Output Production and Duality: Theory and Application. Kluwer Academic, Boston/Dordrecht.

Fraumeni, B. M. (1977, July). The Measurement of Depreciation in the U.S. National Income and Product Accounts. Survey of Current Business, 77, 7-23.

Griliches, Z., \& D. W. Jorgenson. (1966). The explanation of Productivity Change. Review of Economic Studies, $3,249-283$.

Grossman, G. M., \& E. Helpman. (1991). Innovation and Growth in the Global Economy. MIT Press, Cambridge, MA.

Hall, Robert E. (1988). The relation between Price and Marginal Cost in U.S. Industry. Journal of Political 
Economy, 96(5), 921-947. http://dx.doi.org/10.1086/261570

Hall, Robert E. (1990). Invariance Properties of Solow's Productivity Residual. In Diamond, Peter (Ed.), Growth, Productivity, Unemployment (pp. 71-112). Essays to Celebrate Bob Solow's Birthday, MIT Press, Cambridge, MA.

Hall, Robert E., \& Dale W. Jorgenson. (1967). Tax policy and Investment Behavior. American Economic Review, 57(3), 391-414.

Hsieh, Chang-Tai. (1999). Productivity Growth and Factor Prices in East Asia. The American Economic Review, 89(2), 133-138. http://dx.doi.org/10.1257/aer.89.2.133

Hsieh, Chang-Tai. (2002). What Explains the Industrial Revolution in East Asia? Evidence from the Factor Markets. The American Economic Review, 92(3), 502-526. http://dx.doi.org/10.1257/00028280260136372

Hulten, C. R., \& Wyckoff, F. C. (1996). Issues in the Measurement of Economic Depreciation: Introductory Remarks. Economic Inquiry, 34, 10-23. http://dx.doi.org/10.1111/j.1465-7295.1996.tb01361.x

Hulten, Charles R. (2000). Total Factor Productivity: A short biography. Washington DC, National Bureau of Economic Research, 7471.

Jorgenson, D. W., F. M. Gollop, \& B. M. Fraumeni. (1987). Productivity and U.S. Economic Growth. Amsterdam: North-Holland.

Lerner, A. (1934, June). The Concept of Monopoly and the Measurement of Monopoly Power. Review of Economic Studies, 1, 157-173. http://dx.doi.org/10.2307/2967480

Lipsey, Richard G., \& Kenneth I. Carlaw. (2002). The measurement of technological change. Unpublished.

Lucas, R. E., Jr. (1988). On the Mechanism of Economic Development. Journal of Monetary Economy, 22, 3-42. http://dx.doi.org/10.1016/0304-3932(88)90168-7

Marschak, J., \& W. H. Andrews. (1944). Random Simultaneous Equations and the Theory of Productions. Econometrica, 12, 143-205. http://dx.doi.org/10.2307/1905432

Olley, G. Steven, \& Ariel Pakes. (1996). The Dynamics of Productivity in the Telecommunications Equipment Industry. Econometrica, 64, 1263-1297. http://dx.doi.org/10.2307/2171831

Roeger, Werner. (1995). Can Imperfect Competition Explain the Difference Between Primal and Dual Productivity Measures? Estimate for US Manufacturing. Journal of Political Economy, 103, 316-330. http://dx.doi.org/10.1086/261985

Romer, P. M. (1986). Increasing Returns and Long-Run Growth. Journal of Political Economy, 94, 1002-1037. http://dx.doi.org/10.1086/261420

Romer, P. M. (1990). Endogenous Technical Change. Journal of Political Economy, 98, S71-S102. http://dx.doi.org/10.1086/261725

Solow, Robert M. (1956, February). A Contribution to the theory of Economic Growth. Quarterly Journal of Economics, 70, 65-94. http://dx.doi.org/10.2307/1884513

Solow, Robert M. (1957). Technical Change and the Aggregate Production Function. Review of Economics and Statistics, 39, 312-320. http://dx.doi.org/10.2307/1926047

Solow, Robert M. (1960). Investment and Technical Progress. In Arrow, K., Karlin, \& Suppers (Eds.), Mathematical Method in Social Sciences. Stanford University Press.

Young, Alwyn. (1992). A Tale of Two Cities: Factor Accumulation and Technical Change in Hong Kong and Singapore. NBER Macroeconomics Annual, 13-53.

Young, Alwyn. (1995). The Tyranny of Numbers: Confronting the Statistical Realities of the East Asian Growth Experience. Quarterly Journal of Economics, 110(3), 641-668. http://dx.doi.org/10.2307/2946695

Young, Alwyn. (1998). Alternative Estimate of Productivity Growth in the NIC's: A Comment on the Finding of Chang-Tai Hsieh. NBER Working Paper No. 6657. 